\title{
Classificação de argamassas com incorporação de materiais de mudança de fase com base nas suas propriedades físicas, mecânicas e térmicas
}

\author{
Classification of mortars with incorporation of \\ phase change materials based on their \\ physical, mechanical and thermal \\ properties
}

\author{
Sandra Cunha ${ }^{1}$, José Aguiar ${ }^{1}$, \\ Victor Ferreira ${ }^{2}$, António Tadeu ${ }^{3}$
}

\footnotetext{
${ }^{1}$ Universidade do Minho, Campus de Azurém, 4800-058, Guimarães, Minho, Portugal. e-mail: sandracunha86@gmail.com, aguiar@civil.uminho.pt

${ }^{2}$ Universidade de Aveiro, Campus Universitário de Santiago, 3810-193, Aveiro, Aveiro, Portugal. e-mail: victorf@ua.pt

${ }^{3}$ Universidade de Coimbra, Rua Luís Reis Santos - Pólo II da Universidade, 3030-788, Coimbra, Beira Litoral, Portugal. e-mail: tadeu@dec.uc.pt
}

\begin{abstract}
RESUMO
Actualmente, existem várias argamassas disponiveis para aplicação na industria da construção. Estas argamassas podem ser baseadas em diferentes ligantes, possuir diferentes propriedades fisicas e mecânicas e até mesmo outras propriedades especificas. Contudo, a correta selecção de uma argamassa torna-se cada vez mais dificil. Assim, surge a necessidade de classificar diferentes argamassas com base em critérios especificos e num procedimento único. Desta forma, será possivel identificar as argamassas mais apropriadas de acordo com a sua função. Neste trabalho foi utilizado um procedimento de classificação de materiais desenvolvido por Czarnecki e Lukowski, com base numa função de usabilidade. O procedimento de classificação transforma os resultados experimentais de várias propriedades num único valor numérico. Desta forma, os produtos de construção podem ser classificados de acordo com as suas propriedades individuais ou uma combinação optimizada de várias propriedades. Assim, o principal objectivo deste estudo consiste na classificação de argamassas à base de diferentes ligantes com incorporação de materiais de mudança de fase (PCM). Os ligantes estudados foram a cal hidráulica, gesso e cimento. Para cada ligante foram desenvolvidas três argamassas distintas, uma argamassa de referência (0\% PCM), uma argamassa com incorporação de $40 \%$ de PCM e uma argamassa com incorporação de $40 \%$ de PCM e 1\% de fibras. Com base nos resultados foi possivel concluir que a incorporação de PCM afecta o desempenho global das argamassas.
\end{abstract}

Palavras-chave: Argamassas, Materiais de mudança de fase (PCM), Propriedades mêcanicas, Propriedades físicas, Propriedades térmicas.

\section{ABSTRACT}

Currently, there are several mortars available for application in the construction industry. These mortars can be based on different binders, have different physical and mechanical properties and even other specific properties. However, the correct selection of a mortar becomes increasingly difficult. Thus, comes up the need to classify different mortars based on a specific criteria and a single procedure. In this way, it will be possible to identify the most appropriate mortars according to their function. In this research, a materials ranking procedure developed by Czarnecki and Lukowski is applied, based on an usability function. The ranking procedure transforms experimental results of properties into one numerical value. The products can be classified according to their individual properties or even an optimized combination of different properties. Thus, the main purpose of this study was the ranking of mortars based in different binders with incorporation 
of phase change materials. Hydraulic lime, gypsum and cement were the binders studied. For each binder, three different mortars were developed, reference mortars (0\% PCM), mortars with incorporation of $40 \%$ of PCM and mortars with incorporation of $40 \%$ of PCM and $1 \%$ of fibers. Based on the results it was possible to conclude that the incorporation of PCM in mortars changes their global performance.

Keywords: Mortars, Phase change materials (PCM), Mechanical properties, Physical properties, Thermal properties.

\section{INTRODUÇÃO}

Atualmente, existem vários tipos de argamassas possíveis de aplicar como revestimento no interior dos edifícios, o que torna extremamente difícil a seleção do material com comportamento mais adequado. Assim, existe a necessidade de as classificar de forma criteriosa e com base num procedimento único, de forma a evidenciar claramente aquelas que possuem um comportamento mais adequado, tendo em conta a exposição e funções que irão desempenhar após a sua aplicação.

A seleção dos materiais de construção é uma parte importante dos projetos de engenharia civil. A seleção deve ser feita com base no conhecimento profundo das propriedades dos diferentes materiais. Assim, a utilização de um procedimento de classificação contribui para uma seleção mais rigorosa dos materiais disponíveis, establecendo ainda uma ordem entre os vários materiais.

Nos dias de hoje, existe uma enorme preocupação com o elevado consumo de energia, verificado no setor residencial associado às necessidades de aquecimento e arrefecimento dos edifícios. Assim, torna-se necessária a implementação de soluções construtivas que aumentem a eficiência energética dos edifícios. As argamassas com incorporação de materiais de mudança de fase (PCM) aparecem como uma possível solução, na tentativa de resolver, ou pelo menos minimizar, o consumo energético relacionado com os edifícios. A utilização destes materiais permite a regulação da flutuação de temperatura no interior dos edifícios, mantendo-a mais perto da faixa de temperatura desejada, durante um período de tempo mais longo, reduzindo a necessidade de utilizar um equipamento de climatização [1-3]. Esta técnica permite obter edifícios com parâmetros de conforto superiores, melhorando as condições de vida dos ocupantes e sem qualquer dano para o meio ambiente.

A baixa espessura conseguida com a utilização de PCM combinada com a utilização de uma solução de construção flexível, torna possível obter uma maior capacidade de adaptação dos edifícios, tornando a construção tradicional numa construção mais sustentável. A incorporação de PCM em argamassas para revestimento de paredes interiores, permite obter edifícios com uma maior eficiência energética. Portanto, é importante que a indústria da construção seja inovadora e aceite novas soluções construtivas com vista a resolver problemas com vários anos [4]. As argamassas aditivadas com PCM podem ser aplicadas não só na construção de edifícios novos, mas também em operações de reabilitação.

Atualmente, existe uma enorme variedade de PCMs, com diferentes pontos de transição e entalpias [5]. Contudo, nem todos os PCMs existentes podem ser utilizados para o armazenamento térmico. Os materiais de mudança de fase devem possuir um ponto de fusão/solidificação na gama de temperaturas da sua aplicação prática, assim como um elevado calor latente de fusão e condutibilidade térmica. Um PCM ideal deve possuir algumas propriedades termofísicas, cinéticas, químicas, ambientais e económicas desejáveis [6]. Relativamente às propriedades termofísicas é necessário que o PCM seleciona-do possua uma temperatura de transição na gama de temperaturas de operação desejadas, elevado calor de transição por unidade de volume, ele-vado calor sensível, elevada condutibilidade térmica, reduzida variação de volume durante a transição de fase, fusão congruente e estabilidade térmica a longo prazo. Do ponto de vista cinético, o PCM escolhido deve ter uma elevada velocidade de crescimento dos cristais. No que diz respeito às suas propriedades químicas não deverá apresentar degradação após um grande número de ciclos, deverá ser não corrosivo, não inflamável, não tóxico e não explosivo. No que confere às suas propriedades ambientais os materiais de mudança de fase devem apresentar baixo consumo de energia incorporada, facilidade de separação de outros materiais, elevado potencial de reciclagem e baixo impacto ambiental. Finalmente, sob o ponto de vista económico este deve ser abundante, disponível e com baixo custo de aquisição [6-7].

O PCM pode ser incorporado em materiais de construção utilizando diferentes métodos, tais como o encapsulamento, estabilização, incorporação direta e imersão [8]. Na incorporação direta o PCM é diretamente misturado com os materiais de construção durante a sua produção. No entanto, ainda pouco se conhece acerca das potencialidades dos materiais desenvolvidos com base nesta técnica. Por sua vez, a imersão consiste em mergulhar os produtos de construção em PCM líquido, de forma a que estes absorvam o material por capilaridade [7]. Por outro lado, na técnica de estabilização, o PCM e o material de suporte são fundidos e misturados a uma temperatura elevada, seguido de um arrefecimento do material de suporte, até que a mistu- 
ra se torne sólida [8]. Por último, o encapsulamento é o método mais utilizado, sendo que existem duas principais formas de encapsulamento: microencapsulamento e macroencapsulamento [9]. O macroencapsulamento baseia-se na introdução de PCM em tubos, painéis ou outro recipiente de grandes dimensões, geralmente com dimensões superiores a $1 \mathrm{~cm}$ de diâmetro. $\mathrm{O}$ microencapsulamento consiste na colocação de uma pequena massa molecular em pequenas cápsulas, revestidas por polímeros de alto desempenho, com dimensões inferiores a $1 \mathrm{~cm}$ de diâmetro, sendo as suas dimensões preferenciais de 1 a $60 \mu \mathrm{m}$ [7, 10].

Durante os últimos anos têm sido publicados vários estudos de materiais de construção com incorporação de PCM encapsulado. As placas de gesso com incorporação de microcápsulas de PCM foram um dos principais materiais de construção estudados, devido ao seu baixo custo e facilidade de aplicação [11-13]. A incorporação de microcápsulas de PCM em betão e argamassas também foi alvo de investigação [14-17]. Existem também outros estudos com incorporação de PCM em materiais de construção, como por exemplo painéis de PVC, blocos e tijolos [18-20].

As argamassas com incorporação de PCM têm sido alvo de estudo e de interesse para a comunidade científica [11-24]. No entanto, a aplicação de um procedimento de classificação para ordenar o desempenho de diferentes argamassas aditivadas com PCM é uma das principais lacunas de conhecimento. Assim, o principal objetivo deste trabalho consistiu na classificação de diferentes argamassas com base em diferentes ligantes e com incorporação de PCM. Foi aplicado um procedimento de classificação que teve em consideração em simultâneo diferentes propriedades das argamassas, com base numa função de desempenho geral. O procedimento de classificação foi baseado em propriedades relacionadas com o seu comportamento físico, comportamento mecânico, durabilidade e comportamento térmico. As propriedades consideradas foram a densidade, a resistência à flexão, a resistência à compressão, a aderência, a absorção de água por capilaridade, a absorção de água por imersão, a perda de massa relacionada com os ciclos de gelo-degelo e o comportamento térmico, com base na temperatura máxima, temperatura mínima, desfasamento temporal na situação de arrefecimento e aquecimento.

Alguns autores têm vindo a aplicar metodologias específicas para a classificação de diferentes materiais, tendo em consideração as suas funções futuras [26-27].

Aguiar et al. [26] desenvolveram e aplicaram um procedimento de classificação de revestimentos poliméricos para betões, com o intuito de perceber qual o mais conveniente para o aumento da durabilidade do betão. Assim, o estudo comparativo e de classificação foi aplicado a resinas epoxídicas, resinas acrílicas e resinas de silicone. A classificação do desempenho destes materiais foi efetuada com base em várias propriedades, tendo sido possível classificar de acordo com a mesma metodologia materiais muito distintos.

Tendo em conta que este trabalho apresenta várias formulações distintas de argamassas de referência e com incorporação de PCM, surge a necessidade de as classificar considerando as suas propriedades fisicas, mecânicas e térmicas.

Czarnecki et al. [27] referem que a classificação do desempenho de um material com base numa função de usabilidade constitui um procedimento de avaliação multicritério efetivo e conveniente. A utilização desta metodologia de avaliação permite considerar diferentes propriedades e requisitos específicos relacionados com a sua aplicação.

\section{MATERIAIS E MÉTODOS}

\subsection{Materiais}

Nesta investigação foram utilizados três ligantes diferentes: cimento Portland CEM II B-L 32.5N, cal hidráulica NHL5 e gesso.

Tendo como objetivo o conhecimento das microcápsulas de PCM foram efetuados vários ensaios para a sua caracterização. As microcápsulas são constituídas por uma parede em melamina-formaldeído, com temperatura de transição de $24^{\circ} \mathrm{C}$ e entalpia de $147.9 \mathrm{~kJ} / \mathrm{kg}$. Através de ensaios realizados com recurso ao microscópio eletrónico de varrdura de alta resolução, foi possível observar, que o polímero presente nas microcápsulas de PCM apresenta uma textura regular. Com o objetivo de obter dados mais precisos relacionados com as suas dimensões, foram realizados ensaios de granulometria, com recurso a um granulómetro laser. Foi possível observar que as microcápsulas de PCM possuem dimensões entre 5.8-339 $\mu \mathrm{m}$, apresentando uma dimensão média de $43.91 \mu \mathrm{m}$.

A areia utilizada apresentou uma dimensão média de 439,9 $\mu \mathrm{m}$ e uma massa específica real de 2600 $\mathrm{kg} / \mathrm{m}^{3}$. O superplastificante utilizado é baseado em poliacrilato, com densidade de $1050 \mathrm{~kg} / \mathrm{m}^{3}$, comercializado pela BASF e com denominação comercial de Glenium Sky. Por último, as fibras utilizadas são fibras sin- 
téticas de poliamida, com um comprimento de $6 \mathrm{~mm}$ e densidade de $1380 \mathrm{~kg} / \mathrm{m}^{3}$. As fibras utilizadas foram cedidas por uma empresa produtora de argamassas prontas (Weber).

O processo de mistura e fabrico dos provetes para a determinação das várias propriedades das argamassas, foi realizado de acordo normas europeias especificas.

Após o fabrico, todos os provetes foram conservados durante 7 dias em sacos de polietileno, sendo posteriormente colocados em laboratório à temperatura ambiente (cerca de $22^{\circ} \mathrm{C}$ ) durante 21 dias e posteriormente ensaiados aos 28 dias de idade.

\subsection{Composições}

Foram caracterizadas nove composições distintas, com o principal objetivo de determinar o seu desempenho geral (Tabela 1). A selecção das mesmas foi baseada em trabalhos anteriores dos autores [4, 14, 21-24].

As composições utilizadas possuem diferentes teores de PCM e diferentes ligantes. Sendo que, o teor de PCM selecionado foi de $40 \%$ da massa de agregado.

A quantidade de água foi fixada tendo em consideração o valor de espalhamento de $205 \pm 5 \mathrm{~mm}$, determinado segundo a norma europeia EN 1015-3 [25].

Tabela 1: Composição das argamassas $\left(\mathrm{kg} / \mathrm{m}^{3}\right)$.

\begin{tabular}{l|l|l|l|l|l|l|l}
\hline COMPOSIÇÃO & \multicolumn{2}{|l|}{ LIGANTE } & AREIA & PCM & SUPERPLASTIFICANTE & FIBRAS & ÁGUA/LIGANTE \\
\hline CH500-0PCM & Cal Hidráulica & 500 & 1351.1 & 0 & 15 & 0 & 0.54 \\
\hline CH500-40PCM & Cal Hidráulica & 500 & 571.6 & 228.6 & 15 & 0 & 0.62 \\
\hline CH500-40PCM-F & Cal Hidráulica & 500 & 567.2 & 226.9 & 15 & 5 & 0.62 \\
\hline C32.5N500-0PCM & Cimento & 500 & 1418.8 & 0 & 15 & 0 & 0.55 \\
\hline C32.5N500-40PCM & Cimento & 500 & 644.3 & 257.7 & 15 & 0 & 0.56 \\
\hline C32.5N500-40PCM-F & Cimento & 500 & 622.2 & 248.8 & 15 & 5 & 0.59 \\
\hline G500-0PCM & Gesso & 500 & 1360.4 & 0 & 15 & 0 & 0.56 \\
\hline G500-40PCM & Gesso & 500 & 540.1 & 216.0 & 15 & 0 & 0.70 \\
\hline G500-40PCM-F & Gesso & 500 & 535.8 & 214.3 & 15 & 5 & 0.70 \\
\hline
\end{tabular}

\subsection{Procedimento de classificação das argamassas}

A função que permite determinar o desempenho de um material, tendo em consideração uma determinada propriedade é dada pela equação 1 . Assim, para cada propriedade foi estudado o desempenho do material de forma individual, com base no melhor valor $\left(\mathrm{y}_{\text {melhor }}\right)$ e pior valor $\left(\mathrm{y}_{\text {pior }}\right)$, obtidos experimentalmente.

$$
\operatorname{di}(y)=e^{\wedge}(-e)^{\wedge}\left(-\left(y-y_{\text {pior }}\right) /\left(y_{\text {melhor }}{ }^{-} y_{\text {pior }}\right)\right)
$$

Onde:

di(y) - Função de desempenho individual da propriedade;

y - Valor de desempenho da propriedade;

$\mathrm{y}_{\text {pior }}$ - Pior valor de desempenho da propriedade;

$\mathrm{y}_{\text {melhor }}$ - Melhor valor de desempenho da propriedade.

A gama de valores satisfatórios para classificação do desempenho individual de uma determinada propriedade $\mathrm{d}_{\mathrm{y}}$ encontra-se entre 0.37 e 0.69 . Os valores próximos de um apresentam um bom desempenho, sendo que os valores próximos de zero são aqueles que apresentam um pior desempenho.

Após a compreensão do desempenho do material tendo em consideração uma determinada propriedade é necessário aplicar uma análise multicritério, de forma a obter o desempenho geral do material. A função de avaliação do desempenho geral é dada pela equação 2 .

$\mathrm{D}=\mathrm{w}_{1} \times \mathrm{d}_{1}+\mathrm{w}_{2} \times \mathrm{d}_{2}+\ldots+\mathrm{w}_{\mathrm{i}} \times \mathrm{d}_{\mathrm{i}}$

Onde:

D - Função de desempenho global de um material;

$\mathrm{w}_{\mathrm{i}}-$ Fator de ponderação atribuído à propriedade $\mathrm{y}_{\mathrm{i}}$; 
$\mathrm{d}_{\mathrm{i}}$ - Função de desempenho individual da propriedade $\mathrm{y}_{\mathrm{i}}$.

A Tabela 2 mostra as propriedades consideradas neste trabalho. Para utilizar a função geral de desempenho em argamassas, cada propriedade foi formulada em termos quantitativos, establecendo os valores de $\mathrm{y}_{\text {melhor }}$, $\mathrm{y}_{\text {pior }}$ e $\mathrm{w}_{\mathrm{i}}$.

Tabela 2: Propriedades principais consideradas na avaliação do desempenho global das argamassas.

\begin{tabular}{l|l}
\hline PROPRIEDADE & COMPORTAMENTO \\
\hline Massa volúmica $\left(\mathrm{kg} / \mathrm{m}^{3}\right)$ & - \\
\hline Resistência à flexão $(\mathrm{MPa})$ & Comportamento mecânico \\
\hline Resistência à compressão $(\mathrm{MPa})$ & Comportamento mecânico \\
\hline Aderência $(\mathrm{MPa})$ & Comportamento mecânico \\
\hline Coeficiente de absorção capilar $\left(\mathrm{kg} /\left(\mathrm{m}^{2} \cdot \mathrm{min}^{0.5}\right)\right)$ & Durabilidade \\
\hline Absorção de água por imersão $(\%)$ & Durabilidade \\
\hline Perda de massa face a ações de gelo-degelo $(\%)$ & Durabilidade \\
\hline Temperatura máxima $\left({ }^{\circ} \mathrm{C}\right)$ & Comportamento Térmico \\
\hline Temperatura mínima $\left({ }^{\circ} \mathrm{C}\right)$ & Comportamento Térmico \\
\hline Desfasamento temporal na situação de arrefecimento $(\mathrm{min})$ & Comportamento Térmico \\
\hline Desfasamento temporal na situação de aquecimento (min) & Comportamento Térmico \\
\hline
\end{tabular}

\subsection{Procedimento de ensaio das argamassas}

A preparação dos provetes e a realização dos ensaios decorreu em conformidade com a norma europeia EN 1015-11 [28]. Após a sua preparação, todos os elementos de ensaio foram armazenados 7 dias em sacos de polietileno e posteriormente colocados em laboratório à temperatura ambiente $\left(22^{\circ} \mathrm{C}\right)$ durante 21 dias. Os ensaios de determinação das resistências à flexão e compressão foram realizados com controlo de força a uma velocidade de $50 \mathrm{~N} / \mathrm{s}$ e $150 \mathrm{~N} / \mathrm{s}$, respetivamente.

Relativamente à determinação da aderência, a mistura e preparação dos provetes efectuou-se de acordo com a norma europeia EN 1015-12 [29]. Para cada composição estudada foi preparada uma amostra aplicada num subtrato tradicional da industria da construção (tijolo). Após a sua preparação, todos os elementos de ensaio foram armazenados durante 7 dias em sacos de polietileno e posteriormente colocados em laboratório à temperatura ambiente $\left(22^{\circ} \mathrm{C}\right)$ durante 21 dias. Posteriormente, com recurso a uma caroteadora foram preparados 5 provetes circulares com um diâmetro de $50 \mathrm{~mm}$. Os ensaios realizaram-se apenas para as composições de referência ( $0 \%$ de PCM) e para as composições com incorporação de $40 \%$ de PCM e $1 \%$ de fibras de poliamida, uma vez que as composições com incorporação de $40 \%$ de PCM e sem adição de fibras apresentaram fissuras de retracção na superfície, tornando impossível a realização dos ensaios.

Os ensaios de absorção de água por capilaridade foram realizados com base na norma europeia EN 1015-18 [30]. Os elementos de ensaio foram obtidos por flexão de 3 provetes prismáticos, resultando assim em 6 elementos de ensaio para cada composição.

Os ensaios de absorção de água por imersão basearam-se na especificação LNEC E 394 [31]. Os provetes foram obtidos por flexão de 3 provetes prismáticos, resultando assim em 6 elementos de ensaio para cada composição.

A determinação do comportamento das argamassas a ciclos de gelo-degelo foi avaliada com base na es-pecificação europeia CEN/TS 12390-9 [32]. O equipamento utilizado para a realização dos ensaios, foi pro-gramado com uma lei de temperaturas em que cada ciclo de gelo-degelo teve uma duração de $24 \mathrm{~h}$, tendo sido realizados um total de 56 ciclos. Durante cada ciclo de gelo-degelo a temperatura variou entre os $24^{\circ} \mathrm{C}$ e os $-18^{\circ} \mathrm{C}$. Com o intuito de contabilizar a perda de massa de cada provete, estes foram colocados individualmente em recipientes capazes de conter as suas perdas de massa, resultantes da degradação sofrida durante os ensai-os. A quantificação da perda de massa dos provetes sujeitos aos ciclos de temperatura foi realizada através da realização de sucessivas pesagens.

O comportamento térmico foi testado com recurso a uma câmara climática, programada com uma lei de temperatura representativa da estação do ano a ser analisada. Para cada composição, desenvolveu-se uma célula de ensaio em pequena escala feita com um material isolante (poliestireno extrudido) com $3 \mathrm{~cm}$ de espessura. As células possuem uma dimensão de $200 \times 200 \times 200 \mathrm{~mm}^{3}$ e foram revestidas no seu interior com 
uma camada de argamassa de $1 \mathrm{~cm}$ de espessura. Foram ainda colocados termopares no interior e exterior das células para uma rigorosa medição das variações de temperatura. Durante estes ensaios, o PCM atingiu a transição de fase (entre 21 e $24^{\circ} \mathrm{C}$ ) armazenando e liberando a energia do ambiente.

É sabido que a temperatura externa influencia significativamente o comportamento do PCM, já que este material tem grande influência em áreas onde o inverno e o verão são mais rigorosos [33-34]. Assim, com base em dados meteorológicos, realizou-se uma campanha de testes com o objectivo de avaliar o comportamento térmico das argamassas com incorporação de PCM em Portugal, durante a estação de verão. Os dados meteorológicos foram fornecidos pela estação meteorológica instalada na Universidade do Minho em Guimarães, Portugal, com as seguintes coordenadas (latitude: $41^{\circ} 33$ '33.8" N - longitude: $8^{\circ} 23^{\prime} 54.3^{\prime \prime} \mathrm{W}$ ). Para simular a estação de verão, a temperatura mínima atingida foi de $11^{\circ} \mathrm{C}$ e a temperatura máxima foi de $44^{\circ} \mathrm{C}$, tendo sido realizados três ciclos, cada um com uma duração de 24 horas.

\section{RESULTADOS E DISCUSSÃO}

\subsection{Massa volúmica}

A massa volúmica das argamassas foi determinada aos 28 dias de idade, com base na massa e dimensões dos provetes. Foi possivel observar uma diminuição do seu valor com a incorporação de microcápsulas de PCM (Figura 1). A incorporação de $40 \%$ de PCM causou uma diminuição na massa volúmica das argamassas de cerca de $30 \%$ para todos os ligantes testados. Este comportamento pode ser explicado pela baixa densidade do PCM e pelo aumento da quantidade de água utilizada na produção destas argamassas. A incorporação de fibras não causou alterações significativas na massa volúmica, uma vez que o teor incorporado em cada composição é muito baixo.

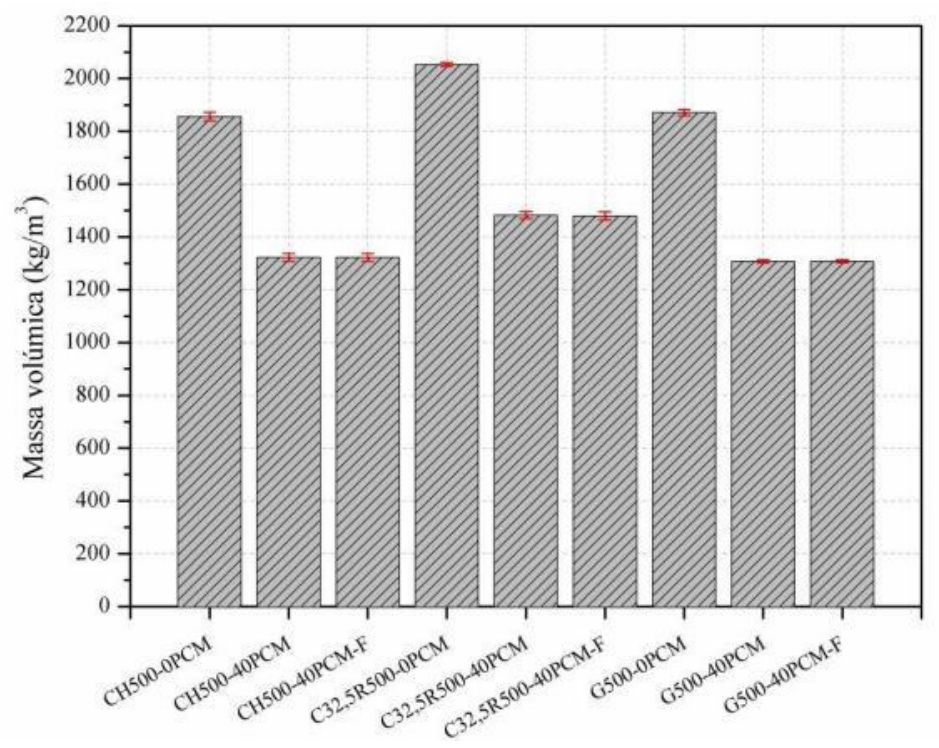

Figura 1: Massa volúmica das argamassas.

\subsection{Resistências à flexão e compressão}

Na Figura 2 observa-se uma diminuição na resistência à flexão causada pela incorporação de PCM. A incorporação de $40 \%$ de microcápsulas de PCM resultou numa diminuição superior a $35 \%$. Relativamente à resistência à compressão (Figura 3), observou-se uma redução significativa com a incorporação de PCM. A incorporação de $40 \%$ de microcápsulas de PCM originou uma diminuição na resistência à compressão superior a 58\%, comparativamente com a argamassa de referência. Este comportamento encontra-se associado à maior necessidade de água das argamassas com incorporação de PCM.

A incorporação de fibras de poliamida não demonstrou alteração significativa na resistencia à flexão e com pressão das argamassas desenvolvidas, no entanto vizulamente foi possivel observar a sua capacidade em se oporem à formação de fissuras. 
O ligante que apresentou menores perdas de resistência à flexão e à compressão foi o cimento. Em contraste, o ligante que apresentou uma maior sensibilidade para a incorporação de microápsulas de PCM e, consequentemente, maiores perdas nas propriedades mecânicas foi o gesso. Este comportamento pode ser justificado pelo aumento da relação água/ligante, causado pela incorporação de PCM . Sendo que, o aumento na quantidade de água com a incorporação de PCM foi mais expressivo para as argamassas à base de gesso e menos expressivo nas argamassas à base de cimento.

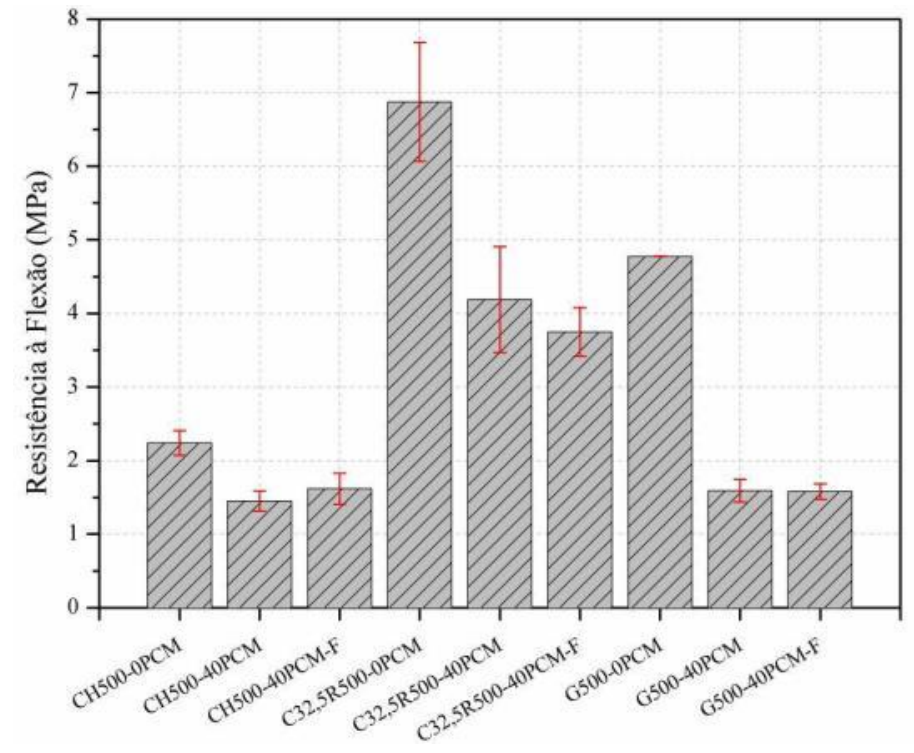

Figura 2: Resistência à flexão das argamassas.

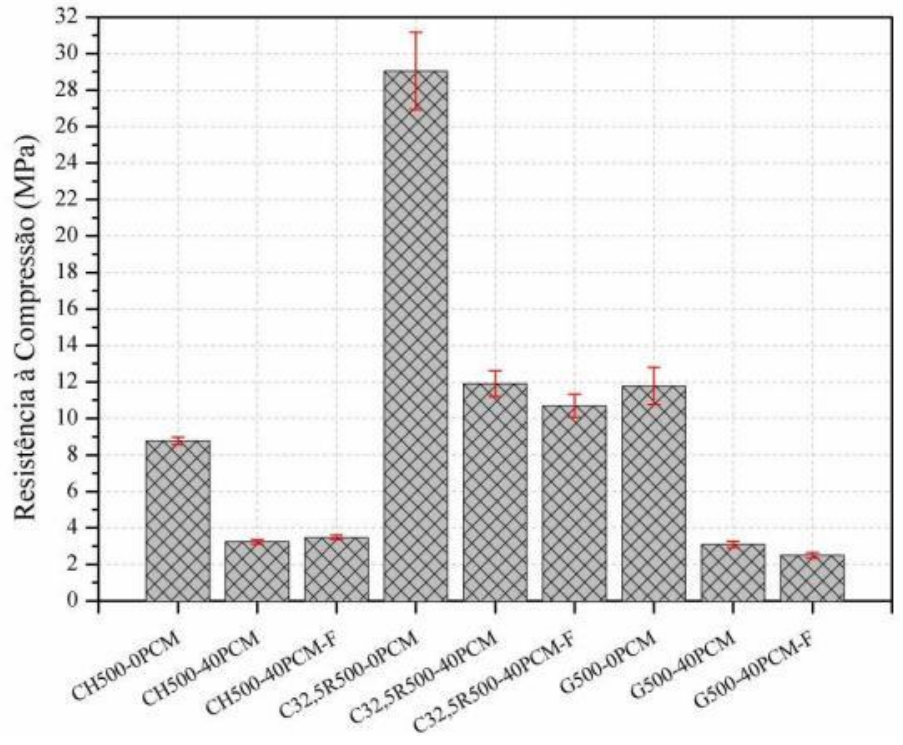

Figura 3: Resistência à compressão das argamassas.

\subsection{Aderência}

A Figura 4 apresenta uma diminuição na aderência com a incorporação de microcápsulas de PCM, sendo que a incorporação de $40 \%$ de PCM conduziu a uma diminuição no valor da aderência de cerca de $50 \%$. Este comportamento encontra-se relacionado com a maior fragilidade das argamassas com incorporação de microcápsulas de PCM, devido ao maior teor de água presente nas mesmas e à menor aderência entre as argamassas de PCM e a matriz da argmassa. 


\subsection{Absorção de água por capilaridade}

A incorporação de $40 \%$ de microcápsulas de PCM causou uma diminuição no coeficiente de absorção capilar de $13 \%$ nas argamassas à base de cal hidráulica e de cerca de 33\% nas argamassas de cimento (Figura 5). Por outro lado, também foi possível observar um aumento no coeficiente de absorção capilar de $15 \%$ para as argamassas à base de gesso. Desta forma foi possível verificar que a incorporação de microcápsulas de PCM não originou o mesmo comportamento em todos os ligantes analisados. Nos ligantes hidráulicos foi possível associar a incorporação de PCM a uma diminuição do coeficiente de absorção de água por capilaridade, sendo que este aumento se verifica mantendo sensivelmente a mesma razão de água/ligante e portanto se encontra diretamente relacionado com a incorporação do material de mudança de fase.

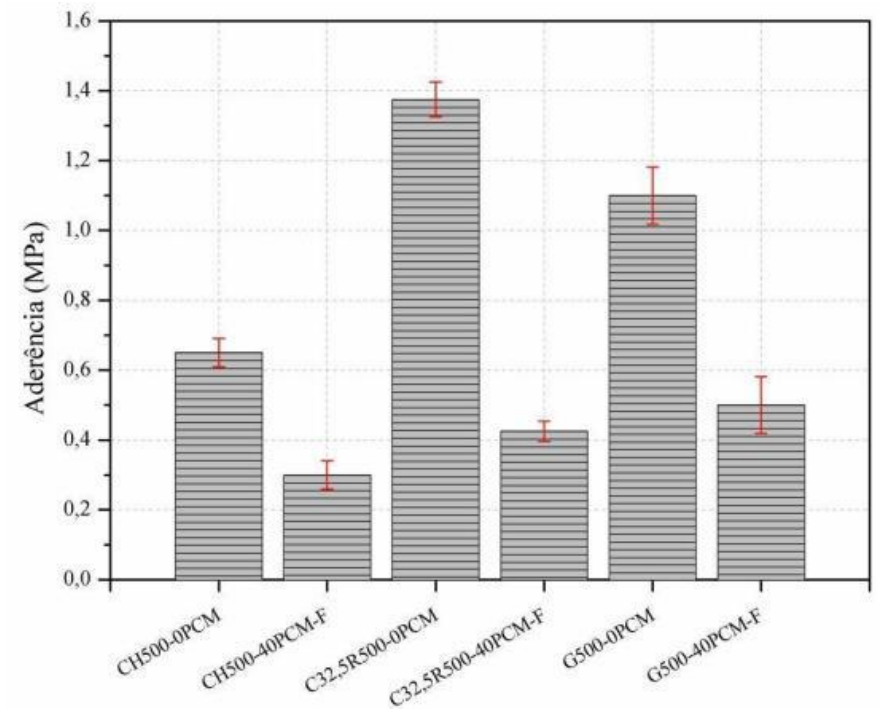

Figura 4: Aderência das argamassas.

Relativamente às argamassas à base de gesso foi possível verificar um aumento do valor do coeficiente de absorção de água por capilaridade, o que se encontra relacionado não só com a presença do material de mudança de fase, mas também com a presença de uma razão água/ligante superior, de forma a se obter uma argamassa com boa trabalhabilidade.

A incorporação de $1 \%$ de fibras de poliamida provocou uma diminuição do coeficente de absorção capilar superior a 4\%. Este comportamento pode ser justificado pelo facto das fibras ocuparem total ou parcialmente alguns dos poros presentes na microestrutura das diferentes argamassas estudadas.

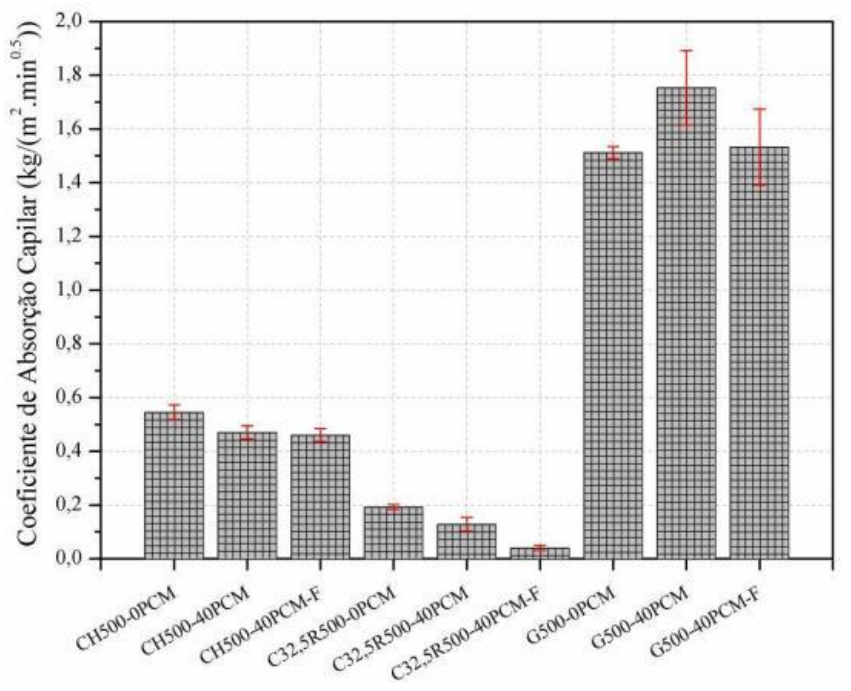

Figura 5: Coeficiente de absorção de água por capilaridade das argamassas. 


\subsection{Absorção de água por imersão}

Na Figura 6 observa-se que a incorporação de 40\% de microcápsulas de PCM em argamassas provocou um aumento na absorção de água superior a $17 \%$. Este comportamento encontra-se associado à presença de um maior teor de água presente nas argamassas dopadas com microcápsulas de PCM.

No entanto, a incorporação de fibras de poliamida resultou numa diminuição da absorção de água superior a 8\%, com excepção das argamassas à base de cal hidráulica, cujo valor não sofreu qualquer alteração. Este comportamento pode ser justificado pelo fato das fibras preencherem e ocuparem parte dos poros das argamassas desenvolvidas.

Também foi possível identificar que as argamassas à base de gesso e argamassas à base de cal hidráulica apresentaram maiores valores de absorção de água. Por outro lado, as argamassas à base de cimento mostraram uma menor absorção de água.

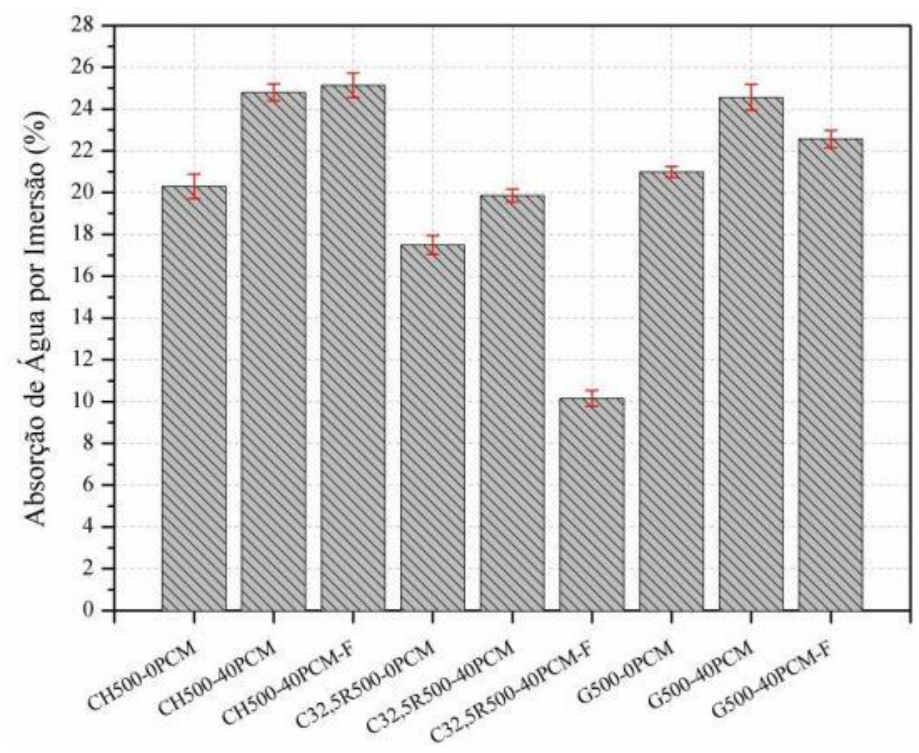

Figura 6: Absorção de água por imersão das argamassas.

\subsection{Gelo-degelo}

A Figura 7 mostra a degradação total sofrida pelos elementos de ensaio das diferentes composições testadas. Verifica-se que a incorporação de PCM origina maiores perdas de material durante a ação de gelo-degelo, demonstrando deste modo uma maior susceptibilidade de ataque. Este comportamento encontra-se relacionado com a facilidade da água em penetrar na argamassa e pode ser evidenciado pelo aumento da porosidade com a incorporação de PCM. A incorporação de fibras originou uma diminuição da perda de massa, associada a uma maior dificuldade de penetração da água. Este comportamento pode justificar-se pela diminuição da porosidade nas argamassas, causada pela incorporação de fibras de poliamida. 


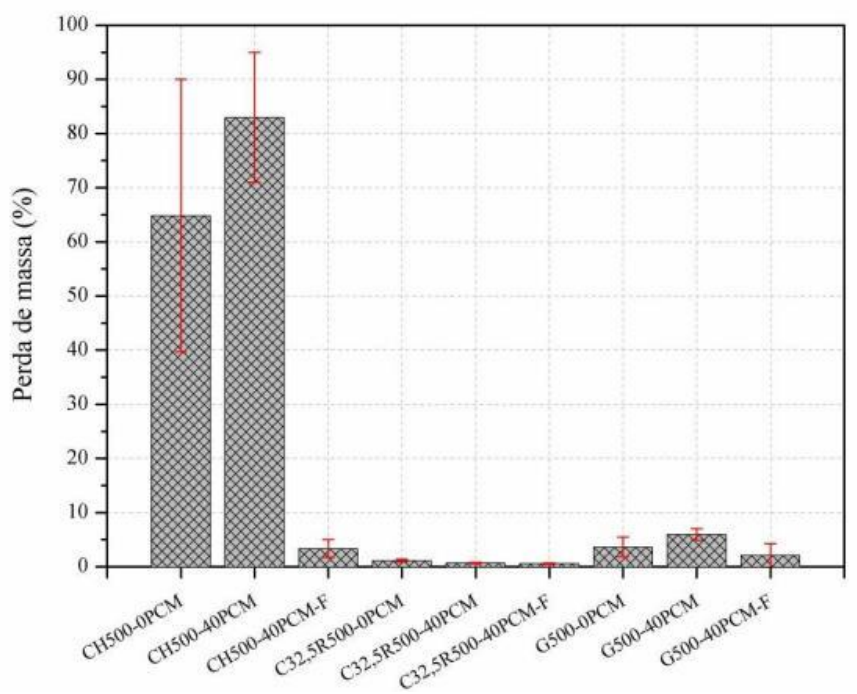

Figura 7: Perda de massa das argamassas face a ações de gelo-degelo.

\subsection{Comportamento térmico}

Na Figura 8, observou-se o comportamento das argamassas numa situação de verão. Para cada ligante foi testada uma composição sem incorporação de PCM e uma composição com 40\% de PCM e 1\% de fibras de poliamida, uma vez que as composições com incorporação de $40 \%$ de PCM e sem adição de fibras apresentaram fissuras na superfície, tornando impossível realizar estes ensaios.
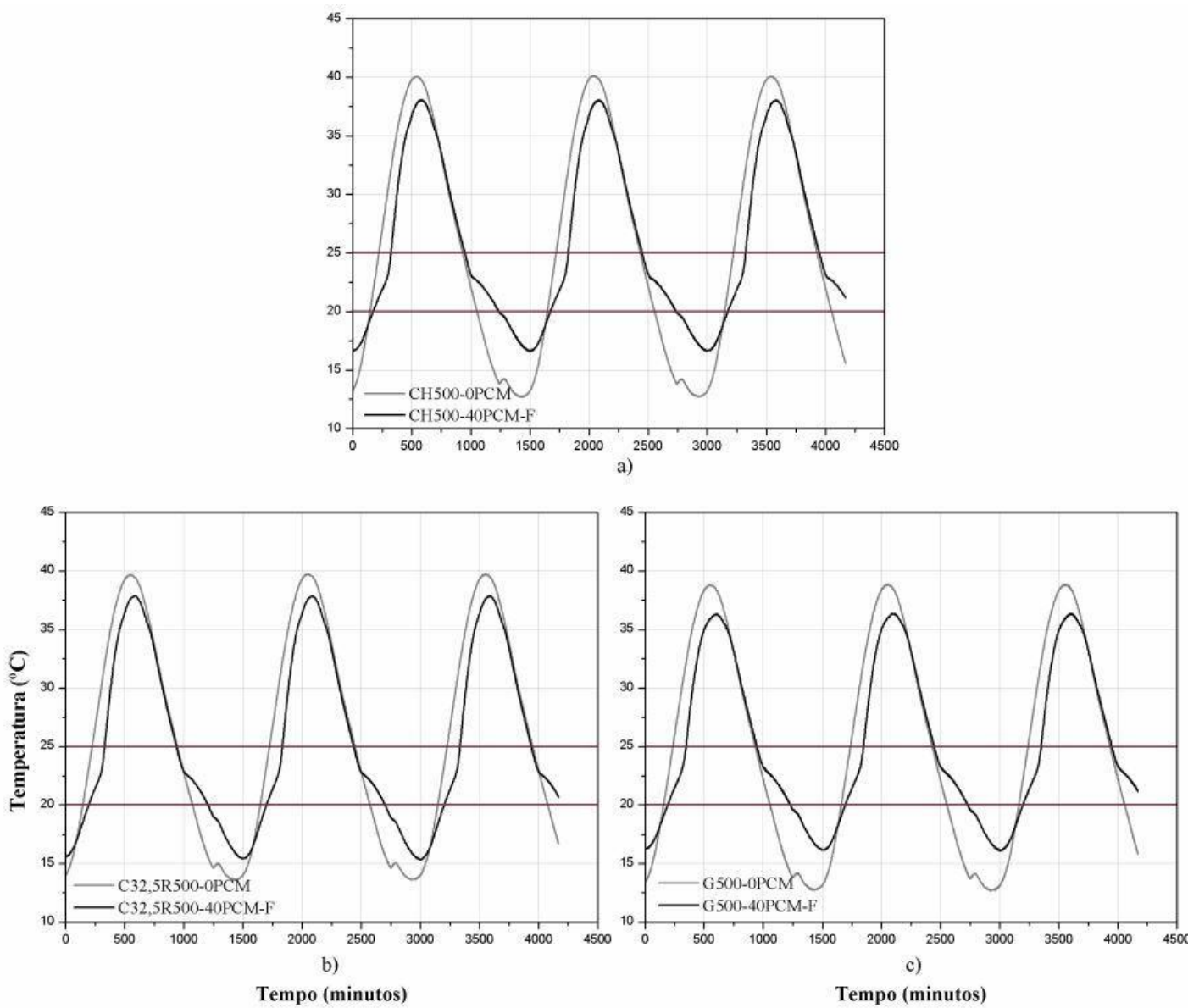

Figura 8: Comportamento térmico de verão: a) Argamassas à base de cal hidráulica; b) Argamassas à base de cimento; c) Argamassas à base de gesso. 
Em todas as composições com incorporação de PCM observa-se que as curvas de temperatura evoluem de forma diferente em relação à curva de temperatura da argamassa de referência. Para a situação de arrefecimento, ou seja, quando a temperatura excede $25^{\circ} \mathrm{C}$, as argamassas com PCM apresentaram uma temperatura máxima mais baixa. Um comportamento semelhante foi verificado para a situação de aquecimento, ou seja, quando a temperatura é inferior a $20^{\circ} \mathrm{C}$, tendo-se verificado um aumento da temperatura mínima nas argamassas com PCM. Desta forma, verifica-se um efeito benéfico da incorporação de PCM em argamassas para revestimento interior porque, as células com PCM não atingiram temperaturas tão extremas como as células de teste revestidas com as argamassas de referência (PCM 0\%). Por outro lado, verificou-se que a temperatura interior permaneceu estável por um período de tempo mais longo. Assim, foi possivel observar uma diminuição da temperatura máxima superior a 5\%, na situação de arrefecimento, e um aumento na temperatura mínima superior a $14 \%$, na situação de aquecimento. Este comportamento traduz-se num tempo de operação mais curto dos sistemas de aquecimento, arrefecimento e ar condicionado quando as argamassas com incorporação de PCM são utilizadas, obtendo-se uma poupança de energia.

Avaliando a influência em termos de tempearturas extremas (temperatura máxima e temperatura mínima), foi possivel observar que as argamassas à base de cal hidráulica apresentaram o melhor desempenho térmico, reduzindo as temperaturas máximas durante a situação de arrefecimento em cerca de 5\% e aumentando as temperaturas mínimas durante a situação de aquecimento em $31 \%$, comparativamente à composição sem incorporação de PCM (Figura 9). No entanto, em todos os ligantes observou-se um aumento na temperatura mínima e uma diminuição na temperatura máxima.
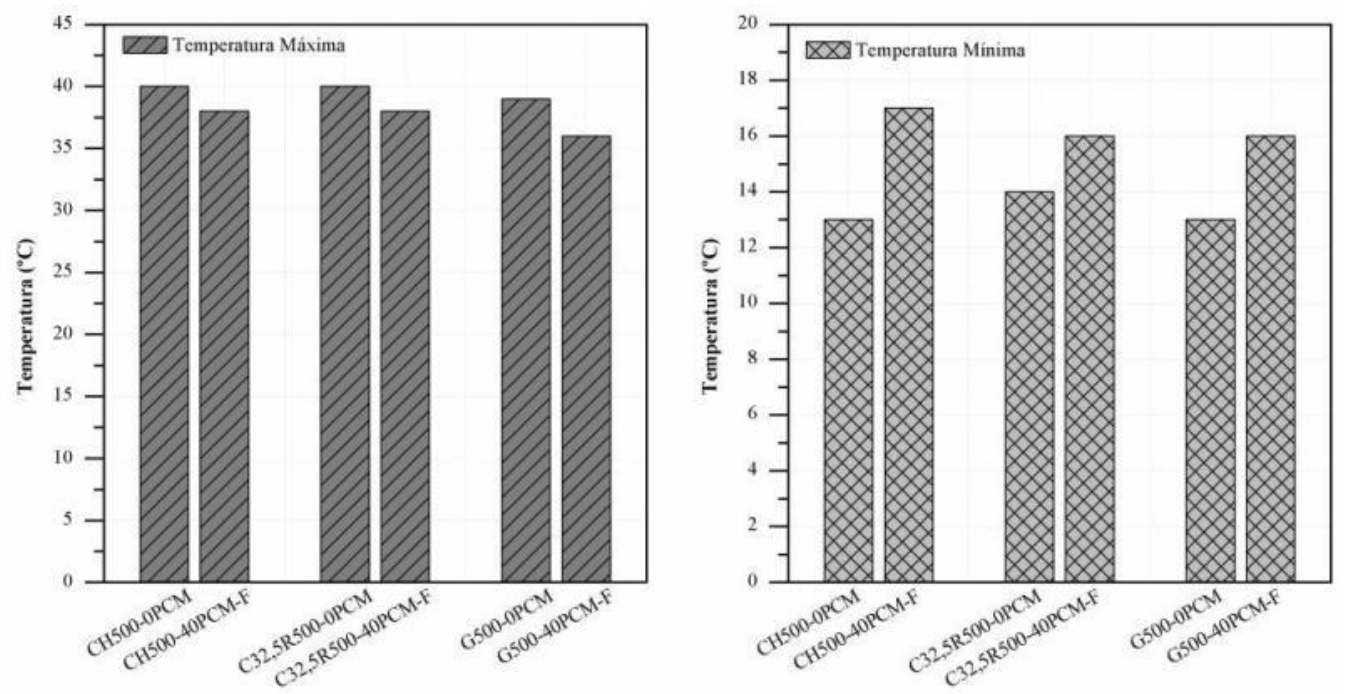

Figura 9: Temperaturas máxima e mínima durante a estação de verão.

Durante estes ensaios, observou-se também um desfasamento temporal das temperaturas máximas e mínimas superiores a 60 minutos durante a situação de arrefecimento e aquecimento (Tabela 3). Importa ainda referir que as argamassas à base de cal hidráulica apresentaram os maiores valores de desfasamento, cerca de 65 minutos na situação de arrefecimento e de 125 minutos na estação de aquecimento. Sabendo-se que, a maior parte do consumo de energia nos edifícios residenciais é utilizada para aquecimento e arrefecimento e que existem tarifas diferenciadas de energia durante o dia e a noite, pode concluir-se que a deslocalização dos consumos elevados e consequentes temperaturas extremas para fora das horas de maior procura apresenta uma clara vantagem econômica. 
Tabela 3: Desfasamento temporal durante a situação de aquecimento e arrefecimento.

\begin{tabular}{l|l|l}
\hline \multirow{2}{*}{ LIGANTE } & DESFASAMENTO TEMPORAL (MINUTOS) \\
\cline { 2 - 3 } & ARREFECIMENTO & AQUECIMENTO \\
\hline CH500-0PCM & 0 & 0 \\
\hline CH500-40PCM & 0 & 0 \\
\hline CH500-40PCM-F & 65 & 125 \\
\hline C32.5N500-0PCM & 0 & 0 \\
\hline C32.5N500-40PCM & 0 & 0 \\
\hline C32.5N500-40PCM-F & 70 & 60 \\
\hline G500-0PCM & 0 & 0 \\
\hline G500-40PCM & 0 & 0 \\
\hline G500-40PCM-F & 60 & 95 \\
\hline
\end{tabular}

\section{CLASSIFICAÇÃO DAS ARGAMASSAS}

A classificação das argamassas foi estabelecida com base no procedimento anteriormente apresentado na secção 2.3. Com base nos resultados apresentados na secção 3 deste trabalho, foi possível determinar o melhor e pior desempenho de cada propriedade, para cada argamassa estudada. Os resultados obtidos são apresentados na Tabela 4.

Neste estudo, foi decidido estabelecer diferentes classificações com base nas principais propriedades das argamassas relacionadas com o seu comportamento mecânico, durabilidade e comportamento térmico. As três propriedades relacionadas com o comportamento mecânico foram as resistências à flexão e à compressão e aderência. A durabilidade foi considerada tendo em conta as absorções de água por capilaridade e imersão, e a resistência ao gelo-degelo. Esta decisão baseou-se na norma portuguesa NP EN 998-1 que considera estas as propriedades mais importantes para argamassas para revestimento interior [35]. O comportamento térmico foi considerado com base nas temperaturas máximas e mínimas e desfasamento temporal verificado para a situação de aquecimento e arrefecimento, tal como foi referido na Tabela 2. É de notar que a massa volumica das argamassas desenvolvidas foi considerada em todas as classificações com a mesma ponderação.

Tabela 4: Propriedades consideradas na avaliação do desempenho global das argamassas.

\begin{tabular}{l|l|l}
\hline PROPRIEDADE & $\mathbf{Y}_{\text {PIOR }}$ & $\mathbf{Y}_{\text {MELHOR }}$ \\
\hline Massa volúmica $\left(\mathrm{kg} / \mathrm{m}^{3}\right)$ & 2054 & 1308 \\
\hline Resistência à flexão $(\mathrm{MPa})$ & 1.45 & 6.87 \\
\hline Resistência à compressão $(\mathrm{MPa})$ & 2.49 & 29.05 \\
\hline Aderência $(\mathrm{MPa})$ & 0 & 1.38 \\
\hline Coeficiente de absorção capilar $\left(\mathrm{kg} /\left(\mathrm{m}^{2} \cdot \mathrm{min}^{0.5}\right)\right)$ & 1.75 & 0.04 \\
\hline Absorção de água por imersão $(\%)$ & 25.1 & 10.2 \\
\hline Perda de massa face a ações de gelo-degelo $(\%)$ & 82.9 & 0.55 \\
\hline Temperatura máxima $\left({ }^{\circ} \mathrm{C}\right)$ & 40 & 36 \\
\hline Temperatura mínima $\left({ }^{\circ} \mathrm{C}\right)$ & 13 & 17 \\
\hline Desfasamento temporal na situação de arrefecimento $(\min )$ & 0 & 70 \\
\hline Desfasamento temporal na situação de aquecimento $(\min )$ & 0 & 125 \\
\hline
\end{tabular}

As Tabelas 5 a 7 apresentam o desempenho individual de cada propriedade para cada composição, calculado de acordo com a equação (1). Tendo em consideração as várias diferenças entre as argamassas, estableceram-se vários níveis de comparação. Assim, foram realizadas diferentes classificações baseadas em diferentes fatores de ponderação para cada propriedade. 
Tabela 5: Desempenho individual da densidade, resistência à flexão, resistência à compressão e aderência.

\begin{tabular}{l|l|l|l|l}
\hline \multicolumn{1}{c|}{$d_{i}$} & DENSIDADE & RESISTÊNCIA À FLEXÃO & RESISTÊNCIA À COMPRESSÃO & ADERÊNCIA \\
\hline CH500-0PCM & 0.46 & 0.42 & 0.45 & 0.54 \\
\hline CH500-40PCM & 0.69 & 0.37 & 0.38 & 0.37 \\
\hline CH500-40PCM-F & 0.69 & 0.38 & 0.38 & 0.45 \\
\hline C32.5N500-0PCM & 0.37 & 0.69 & 0.69 & 0.69 \\
\hline C32.5N500-40PCM & 0.63 & 0.55 & 0.50 & 0.37 \\
\hline C32.5N500-40PCM-F & 0.63 & 0.52 & 0.48 & 0.48 \\
\hline G500-0PCM & 0.46 & 0.58 & 0.49 & 0.64 \\
\hline G500-40PCM & 0.69 & 0.38 & 0.38 & 0.37 \\
\hline G500-40PCM-F & 0.69 & 0.38 & 0.37 & 0.51 \\
\hline
\end{tabular}

Foram realizadas quatro avaliações distintas, sendo que numa primeira classificação considerou-se mais relevante o comportamento mecânico. A segunda classificação considerou a durabilidade como o aspecto mais importante. A terceira classificação considerou o comportamento térmico como o aspecto predominante. É de notar que nestas classificações, as propriedades principais possuem um fator de ponderação maior, porém as propriedades restantes não foram desconsideradas. Contudo, é importante obter uma argamassa com alta resistência mecânica, durabilidade adequada e alto desempenho térmico para uma correcta aplicação na indústria da construção. Assim, foi realizada a quarta classificação, em que se considerou o comportamento global, atribuindo o mesmo factor de ponderação a todas as propriedades.

Tabela 6: Desempenho individual do coeficiente de absorção de água por capilaridade, absorção de água por imersão e perda de massa face a ações de gelo-degelo.

\begin{tabular}{l|l|l|l}
\hline \multicolumn{1}{c|}{$d_{i}$} & $\begin{array}{l}\text { COEFICIENTE DE ABSORÇÃO } \\
\text { DE ÁGUA POR CAPILARIDADE }\end{array}$ & $\begin{array}{l}\text { ABSORÇÃO DE ÁGUA } \\
\text { POR IMERSÃO }\end{array}$ & $\begin{array}{l}\text { PERDA DE MASSA } \\
\text { FACE A AÇÕES } \\
\text { GELO-DEGELO }\end{array}$ \\
\hline CH500-0PCM & 0.61 & 0.48 & 0.45 \\
\hline CH500-40PCM & 0.62 & 0.38 & 0.37 \\
\hline CH500-40PCM-F & 0.62 & 0.37 & 0.68 \\
\hline C32.5N500-0PCM & 0.67 & 0.55 & 0.69 \\
\hline C32.5N500-40PCM & 0.68 & 0.50 & 0.69 \\
\hline C32.5N500-40PCM-F & 0.69 & 0.69 & 0.69 \\
\hline G500-0PCM & 0.42 & 0.47 & 0.68 \\
\hline G500-40PCM & 0.37 & 0.38 & 0.68 \\
\hline G500-40PCM-F & 0.42 & 0.43 & 0.69 \\
\hline
\end{tabular}

Tabela 7: Desempenho individual das propriedades térmicas: temperatura máxima, temperatura mínima, desfasamento temporal na situação de arrefecimento e desfasamento temporal na situação de aquecimento.

\begin{tabular}{l|l|l|l|l}
\hline \multicolumn{1}{c|}{$\boldsymbol{D}_{\boldsymbol{I}}$} & $\begin{array}{l}\text { TEMPERATURA } \\
\text { MÁXIMA }\end{array}$ & $\begin{array}{l}\text { TEMPERATURA } \\
\text { MÍNIMA }\end{array}$ & $\begin{array}{l}\text { DESFASAMENTO } \\
\text { TEMPORAL NA } \\
\text { SITUAÇÃO DE } \\
\text { ARREFECIMENTO }\end{array}$ & $\begin{array}{l}\text { DESFASAMENTO } \\
\text { TEMPORAL NA } \\
\text { SITUAÇÃO DE } \\
\text { AQUECIMENTO }\end{array}$ \\
\hline CH500-0PCM & 0.37 & 0.37 & 0.37 & 0.37 \\
\hline CH500-40PCM & 0.37 & 0.37 & 0.37 & 0.37 \\
\hline CH500-40PCM-F & 0.55 & 0.69 & 0.67 & 0.69 \\
\hline C32.5N500-0PCM & 0.37 & 0.46 & 0.37 & 0.37 \\
\hline C32.5N500-40PCM & 0.55 & 0.46 & 0.37 & 0.37 \\
\hline C32.5N500-40PCM-F & 0.55 & 0.62 & 0.69 & 0.54 \\
\hline
\end{tabular}




\begin{tabular}{l|l|l|l|l}
\hline G500-0PCM & 0.46 & 0.37 & 0.37 & 0.37 \\
\hline G500-40PCM & 0.46 & 0.37 & 0.37 & 0.37 \\
\hline G500-40PCM-F & 0.69 & 0.63 & 0.65 & 0.63 \\
\hline
\end{tabular}

\subsection{Classificação baseada no comportamento mecânico}

A Tabela 8 apresenta os fatores de ponderação considerados para a classificação com base no comportamento mecânico.

A Figura 10 apresenta o desempenho das argamassas. Em todos os ligantes foi possivel observar uma diminuição superior a $12 \%$ do desempenho global com a incorporação de PCM. Esta situação pode ser explicada pela diminuição da resistencia à flexão, compressão e aderência das argamassas com incorporação de PCM. Por outro lado, a incorporação de $1 \%$ de fibras causou um efeito positivo no desempenho global das argamassas, evidenciado por um aumento superior a 11\%. Esta situação encontra-se relacionada com o aumento das resistências mecânicas das argamassas com incorporação de fibras, mas essencialmente relacionada com o melhor desempenho nas propriedades relacionadas com a durabilidade, uma vez que também foram consideradas nesta classificação

Observa-se ainda, que a composição à base de cimento e sem PCM (C32.5N500-0PCM) apresentou o melhor desempenho. Este comportamento relaciona-se com os elevados valores desta argamassa para todas as propriedades dominantes. Por outro lado, a argamassa à base de cal hidráulica com incorporação de PCM (CH500-40PCM) apresenta o pior desempenho, uma vez que possui uma resistência à compressão e flexão menor e foi impossível a realização dos ensaios de aderência..

Tabela 8: Factores de ponderação da classificação baseada no comportamento mecânico.

\begin{tabular}{l|l}
\hline PROPRIEDADE & $\mathbf{W}_{\mathbf{l}}$ \\
\hline Densidade $\left(\mathrm{kg} / \mathrm{m}^{3}\right)$ & 0.05 \\
\hline Resistência à flexão $(\mathrm{MPa})$ & 0.20 \\
\hline Resistência à compressão $(\mathrm{MPa})$ & 0.20 \\
\hline Aderência $(\mathrm{MPa})$ & 0.20 \\
\hline Coeficiente de absorção capilar $\left(\mathrm{kg} /\left(\mathrm{m}^{2} . \mathrm{min}^{0.5}\right)\right)$ & 0.05 \\
\hline Absorção de água por imersão $(\%)$ & 0.05 \\
\hline Perda de massa face a ações de gelo-degelo $(\%)$ & 0.05 \\
\hline Temperatura máxima $\left({ }^{\circ} \mathrm{C}\right)$ & 0.05 \\
\hline Temperatura mínima $\left({ }^{\circ} \mathrm{C}\right)$ & 0.05 \\
\hline Desfasamento temporal na situação de arrefecimento $(\mathrm{min})$ & 0.05 \\
\hline Desfasamento temporal na situação de aquecimento $(\min )$ & 0.05 \\
\hline
\end{tabular}




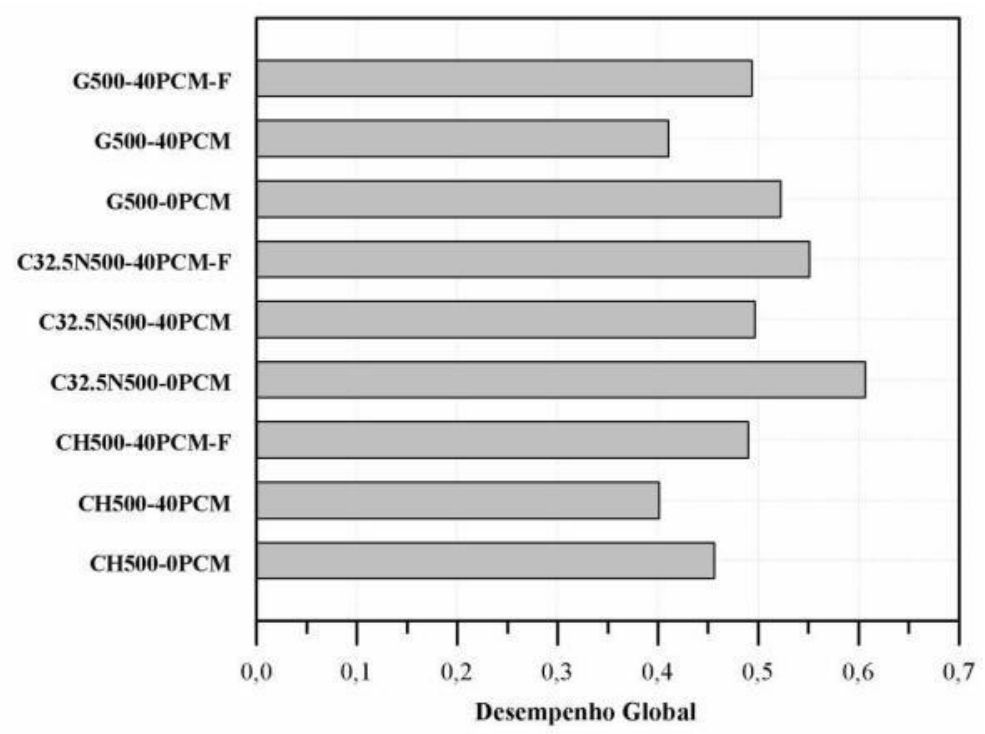

Figura 10: Desempenho global da classificação baseada no comportamento mecânico.

\subsection{Classificação baseada na durabilidade}

A Tabela 9 apresenta os factores de ponderação considerados para a classificação com base na durabilidade. A Figura 11 apresenta o desempenho global das argamassas, tendo sido possivel observar que a composição à base de cimento com incorporação de PCM e fibras (C32.5N500-40PCM-F) apresenta o melhor desempenho. Em contraste, a argamassas à base de cal hidráulica com incorporação de 40\% de PCM (CH50040PCM) apresentou o pior desempenho.

Observou-se que a incorporação de PCM origina alguma fragilidade no desempenho global das argamassas, resultando num decrescimo superior a 4\%. Esta situação pode ser explicada pela menor resistência das composições com PCM aos ensaios de gelo-degelo e ao aumento da absorção de água por imersão, permitindo uma maior facilidade na penetração dos agentes agressivos. Mais uma vez, a incorporação de fibras mostra ser bastante positiva, resultando num aumento do desempenho global das argamassas superior a $14 \%$. Este comportamento encontra-se associado à diminuição da absorção de água por imersão e menores perdas de massa durante as ações de gelo-degelo.

\subsection{Classificação baseada no comportamento térmico}

A Tabela 10 apresenta os fatores de ponderação considerados para a classificação baseada no comportamento térmico. A Figura 12 ilustra o desempenho global das argamassas, sendo que foi possível observar que as argamassas de cal hidráulica, gesso e cimento com incorporação de 40\% de PCM e 1\% de fibras (CH50040PCM-F, G500-40PCM-F e C32.5N500-40PCM-F) possuem o melhor desempenho. Em contrapartida, as argamassas à base de cal hidráulica com incorporação de $40 \%$ de PCM e sem incorporação de fibras (CH500-40PCM) apresentaram o pior desempenho. Esta situação pode ser explicada pela impossibilidade de realizar os ensaios de comportamento térmico em argamassas com incorporação de PCM e sem fibras, devido à sua elevada fissuração. Observou-se ainda, que a incorporação de $40 \%$ de PCM e 1\% de fibras de poliamida causou uma melhoria no desempenho global das argamassas, resultando num aumento superior a $26 \%$. Este comportamento encontra-se associado à capacidade de armazenamento e liberação de energia do PCM.

Tabela 9: Factores de ponderação da classificação baseada na durabilidade.

\begin{tabular}{l|l}
\hline PROPRIEDADE & $\mathbf{W}_{\mathbf{l}}$ \\
\hline Densidade $\left(\mathrm{kg} / \mathrm{m}^{3}\right)$ & 0.05 \\
\hline Resistência à flexão $(\mathrm{MPa})$ & 0.05 \\
\hline Resistência à compressão $(\mathrm{MPa})$ & 0.05 \\
\hline Aderência $(\mathrm{MPa})$ & 0.05 \\
\hline Coeficiente de absorção capilar $\left(\mathrm{kg} /\left(\mathrm{m}^{2} . \mathrm{min}^{0.5}\right)\right)$ & 0.20 \\
\hline
\end{tabular}




\begin{tabular}{l|l}
\hline Absorção de água por imersão $(\%)$ & 0.20 \\
\hline Perda de massa face a ações de gelo-degelo $(\%)$ & 0.20 \\
\hline Temperatura máxima $\left({ }^{\circ} \mathrm{C}\right)$ & 0.05 \\
\hline Temperatura mínima $\left({ }^{\circ} \mathrm{C}\right)$ & 0.05 \\
\hline Desfasamento temporal na situação de arrefecimento $(\mathrm{min})$ & 0.05 \\
\hline Desfasamento temporal na situação de aquecimento $(\min )$ & 0.05 \\
\hline
\end{tabular}

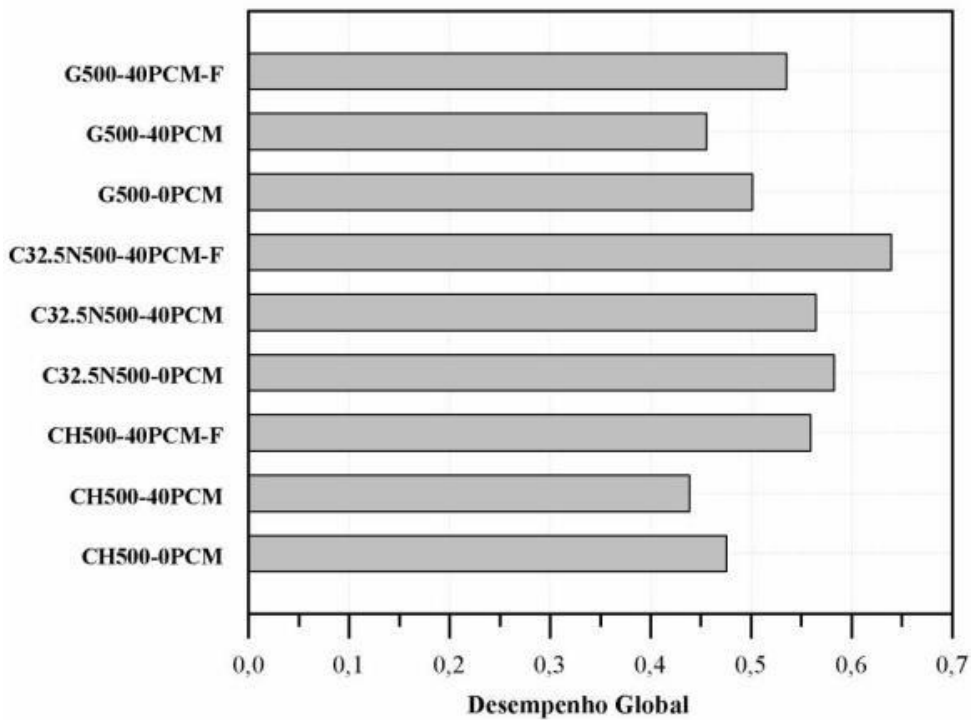

Figura 11: Desempenho global da classificação baseada na durabilidade.

\subsection{Classificação generalista}

A Tabela 11 mostra os fatores de ponderação considerados para a classificação generalista baseada em todas as propriedades avaliadas para as diferentes argamassas.

A Figura 13 apresenta o desempenho global das argamassas com base numa classificação generalista.

Em todos os ligantes verificou-se um maelhor desempenho para as argamassas com incorporação de PCM e fibras, devido à sua contribuição benéfica no desempemho térmico. Observou-se também que as argmassas sem incorporação de PCM apresentam um desempenho intermédio, devido à sua grande contrubuição relacionada com as caracteristicas mecânicas. Por ultimo, as argamassas mais frágeis são as argamassas com incorporação de $40 \%$ de PCm devido à ausencia de uma contribuição no desempenho térmico e um menor desempenho mecânico.

Tabela 10: Factores de ponderação da classificação baseada no comportamento térmico.

\begin{tabular}{l|l}
\hline PROPRIEDADE & $\mathbf{W}_{\mathbf{l}}$ \\
\hline Densidade $\left(\mathrm{kg} / \mathrm{m}^{3}\right)$ & 0.05 \\
\hline Resistência à flexão $(\mathrm{MPa})$ & 0.05 \\
\hline Resistência à compressão $(\mathrm{MPa})$ & 0.05 \\
\hline Aderência $(\mathrm{MPa})$ & 0.05 \\
\hline Coeficiente de absorção capilar $\left(\mathrm{kg} /\left(\mathrm{m}^{2} . \mathrm{min}^{0.5}\right)\right)$ & 0.05 \\
\hline Absorção de água por imersão $(\%)$ & 0.05 \\
\hline Perda de massa face a ações de gelo-degelo $(\%)$ & 0.05 \\
\hline Temperatura máxima $\left({ }^{\circ} \mathrm{C}\right)$ & 0.16 \\
\hline Temperatura mínima $\left({ }^{\circ} \mathrm{C}\right)$ & 0.16 \\
\hline Desfasamento temporal na situação de arrefecimento (min) & 0.16 \\
\hline Desfasamento temporal na situação de aquecimento (min) & 0.16 \\
\hline
\end{tabular}




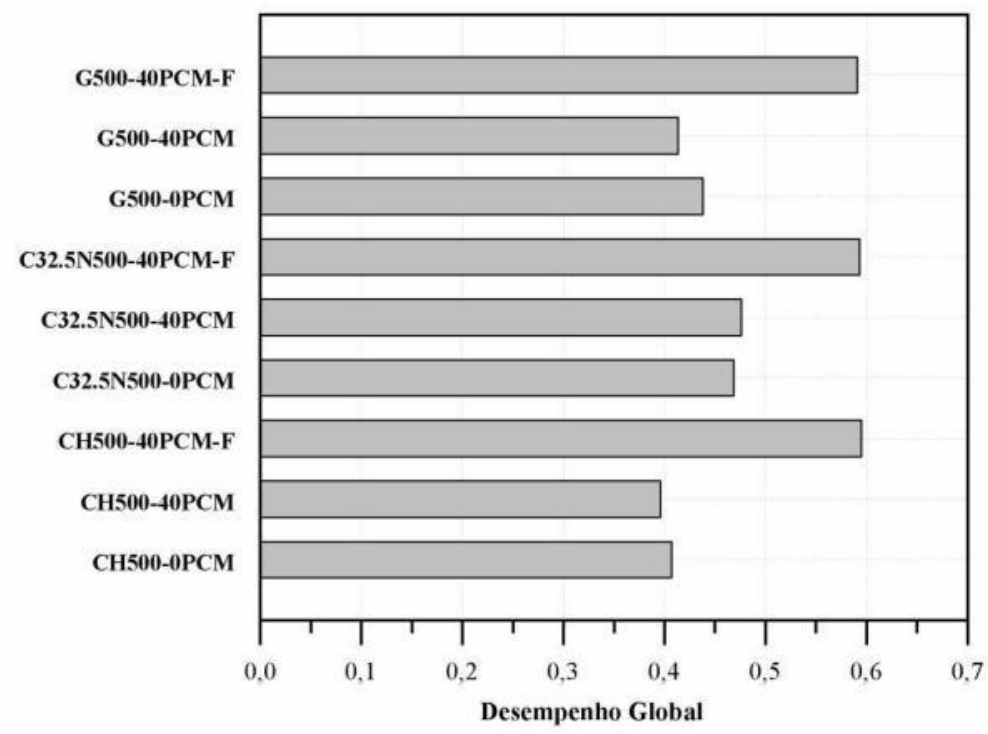

Figura 12: Desempenho global da classificação baseada no comportamento térmico.

Tabela 11: Factores de ponderação da classificação baseada no comportamento generalista.

\begin{tabular}{l|l}
\hline PROPRIEDADE & $\mathbf{W}_{\mathbf{l}}$ \\
\hline Densidade $\left(\mathrm{kg} / \mathrm{m}^{3}\right)$ & 0.09 \\
\hline Resistência à flexão $(\mathrm{MPa})$ & 0.09 \\
\hline Resistência à compressão $(\mathrm{MPa})$ & 0.09 \\
\hline Aderência $(\mathrm{MPa})$ & 0.09 \\
\hline Coeficiente de absorção capilar $\left(\mathrm{kg} /\left(\mathrm{m}^{2} \cdot \mathrm{min}^{0.5}\right)\right)$ & 0.09 \\
\hline Absorção de água por imersão $(\%)$ & 0.09 \\
\hline Perda de massa face a ações de gelo-degelo $(\%)$ & 0.09 \\
\hline Temperatura máxima $\left({ }^{\circ} \mathrm{C}\right)$ & 0.09 \\
\hline Temperatura mínima $\left({ }^{\circ} \mathrm{C}\right)$ & 0.09 \\
\hline Desfasamento temporal na situação de arrefecimento (min) & 0.09 \\
\hline Desfasamento temporal na situação de aquecimento (min) & 0.09 \\
\hline
\end{tabular}

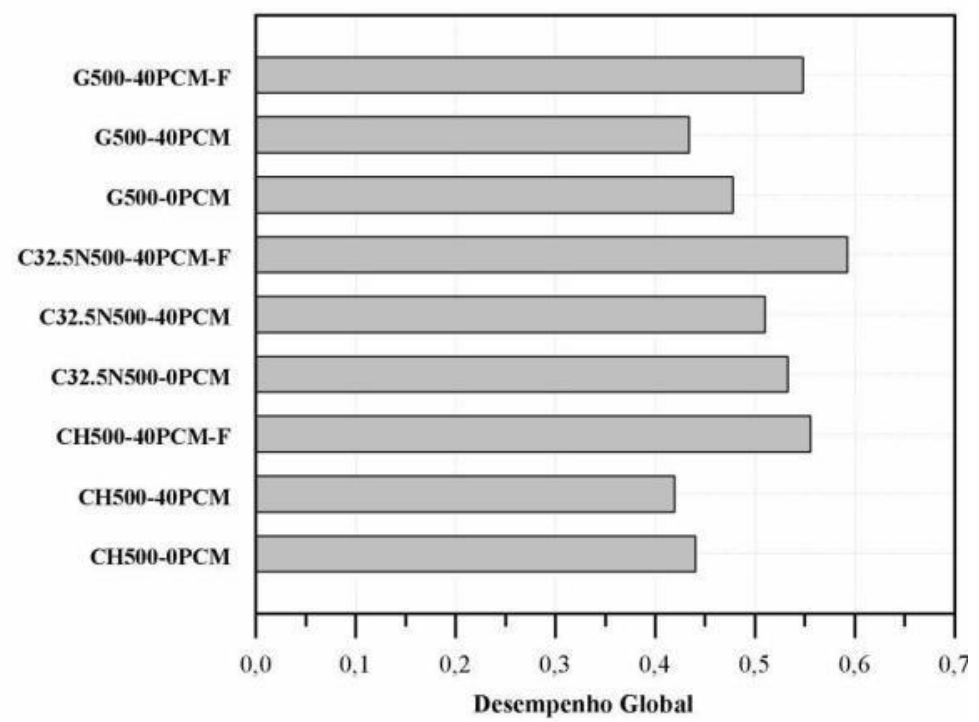

Figura 13: Desempenho global da classificação generalista. 
Em suma, observou-se que as argamassas de cimento com incorporação de $40 \%$ de PCM e $1 \%$ de fibras de poliamida (C32.5N500-40PCM-F) apresentam o melhor desempenho. Por outro lado, as argamassas à base de cal hidráulica com incorporação de 40\% de PCM (CH500-40PCM) revelaram o pior desempenho.

\section{CONCLUSÃO}

A utilização deste procedimento de classificação permitiu, em todos os casos analisados, estabelecer comparações entre as argamassas estudadas. A quantificação dos critérios de seleção do material torna a escolha mais objetiva e independente de sensações subjetivas. O conjunto de critérios pode ser alargado, para ter em conta outros aspectos ou características das argamassas. A inserção de tais critérios poderia alterar drasticamente a classificação das argamassas. Este processo de classificação certamente apresenta uma valiosa ferramenta para a avaliação de desempenho de diferentes materiais.

Relativamente à classificação baseada no comportamento mecânico e durabilidade, concluiu-se que as argamassas à base de cimento apresentam o melhor desempenho, comparativamente com as argamassas à base de outros ligantes. Esta situação pode ser justificada pelas elevadas resistências mecânicas, baixas perdas de massa durante os ensaios de gelo-degelo e menor absorção de água por imersão. O pior desempenho global foi apresentado pelas argamassas à base de cal hidráulica, devido às menores resistências mecânicas e maiores perdas durante as ações de gelo-degelo. Nestas classificações, concluiu-se que as argamassas de referência e as argamassas com incorporação de PCM e fibras apresentaram, em todas as situações, um melhor desempenho em relação às argamassas apenas com incorporação de PCM.

De acordo com a classificação baseada no comportamento térmico, observa-se que as argamassas com incorporação de PCM e fibras apresentam sempre um melhor desempenho em relação às argamassas de referência. A argamassa de cimento com incorporação de PCM e fibras apresentou o melhor desempenho global. Este resultado é justificado pelo bom desempenho térmico das argamassas, mas também pelo bom comportamento mecânico e durabilidade.

Globalmente, em relação à classificação com base em todas as propriedades, verificou-se que as argamassas à base de cimento apresentaram o melhor desempenho e as argamassas à base de cal hidráulica o pior desempenho.

Finalmente, pode concluir-se que as argamassas com incorporação de PCM e fibras, mesmo com um desempenho global inferior em alguns casos em comparação com as argamassas de referência, apresentam sempre um bom desempenho, permitindo-nos assegurar a sua adequação para a indústria da construção com maior facilidade e segurança.

\section{AGRADECIMENTOS}

Os autores desejam expressar os seus agradecimentos à Fundação para a Ciência e Tecnologia (FCT) pelo financiamento deste trabalho no âmbito da bolsa de doutoramento SFRH/BD/95611/2013.

\section{BIBLIOGRAFIA}

[1] LUCAS, S., FERREIRA, V. M., AGUIAR, J., "Latent heat storage in PCM containing mortars - Study of microstructural modifications", Energy and Buildings, n. 1, v. 66, pp. 724-731, Nov. 2013.

[2] SÁ, A., AZENHA, M., SOUSA, H., et al., "Thermal enhancement of plastering mortars with Phase Change Materials: Experimental and numerical approach”, Energy and Buildings, n. 1, v. 49, pp. 16-27, Jun. 2012.

[3] KHERADMAND, M., AZENHA, M., AGUIAR, J., et al., "Thermal behavior of cement based plastering mortar containing hybrid microencapsulated phase change materials", Energy and Buildings, n. 1, v. 84, pp. 526-536, Dec. 2014.

[4] CUNHA, S., AGUIAR, J., FERREIRA, V., et al., "Influence of the type of phase change materials microcapsules on the properties of lime-gypsum thermal mortars", Advanced Engineering Materials, n. 4, v. 16, pp. 433-441, 2014.

[5] KASAEIAN, A., BAHRAMI, L., POURFAYAZ, F., et al., "Experimental studies on the applications of PCMs and nano-PCMs in buildings: A critical review”, Energy and Buildings, v. 154, pp. 96-112, 2017.

[6] CUNHA, S., AGUIAR, J., FERREIRA, V., et al., "Argamassas com incorporação de Materiais 
de Mudança de Fase (PCM): Caracterização física, mecânica e durabilidade", Revista Matéria, n. 1, v.20, pp. 245-261, 2015.

[7] CABEZA, L., CASTELL, A., BARRENECHE, C., et al., "Materials used as PCM in thermal energy storage in buildings: A review", Renewable and Sustainable Energy Reviews, v. 15, pp. 1675-1695, 2011.

[8] MEMON, S. A., "Phase change materials integrated in building walls: A state of the art review", Renewable and Sustainable Energy Reviews, v. 31, pp. 870-906, 2014.

[9] HAWES, D., BANU, D., FELDMAN, D., "Latent heat storage in concrete", Solar Energy Materials, v. 19, pp. 335-348, 1989.

[10] TYAGI, V., KAUSHIK, S., TYAGI, S., AKIYAMA, T., "Development of phase change materials based microencapsulated technology for buildings: A review", Renewable and Sustainable Energy Reviews, v. 15, pp. 1373-1391, 2011.

[11] FANG, G., TANG, F., CAO, L., "Preparation, thermal properties and applications of shape-stabilized thermal energy storage materials", Renewable and Sustainable Energy Reviews, v. 40, pp. 237-259, 2014.

[12] ATHIENITIS, A. K., LIU, C., HAWES, D., et al., "Investigation of the Thermal Performance of a Passive Solar Test-Room with Wall Latent Heat Storage", Building and Environment, v. 32, pp. 405-410, 1997.

[13] SHILEI, L., NENG, Z., GUOHUI, F., "Impact of Phase Change Wall Room on Indoor Thermal Environment in winter", Energy and Buildings, v. 38, pp. 18-24, 2006.

[14] CUNHA, S., ALVES, V., AGUIAR, J., et al., "Use of phase change materials microcapsules in aerial lime and gypsum mortars", Cement Wapno Beton, Special Issue, pp. 17-21, 2012.

[15] DARKWA, K., O'CALLAGHAN, P., TETLOW, D., "Phase-change drywalls in a passive-solar building", Applied Energy, v. 83, pp. 425-435, 2006.

[16] LAI, C., CHEN, R.H., LIN, C., "Heat transfer and thermal storage behaviour of gypsum boards incorporating micro-encapsulated PCM”, Energy and Buildings, v. 42, pp. 1259-1266, 2010.

[17] ENTROP, A., BROUWERS, H., REINDERS, A., "Experimental research on the use of microencapsulated Phase Change Materials to store solar energy in concrete floors and to save energy in Dutch houses", Solar Energy, v. 85, pp. 1007-1020, 2011.

[18] CUNHA, S., AGUIAR, J., FERREIRA, V., et al., "Influence of Adding Encapsulated Phase Change Materials in Aerial Lime based Mortars", Advanced Materials Research, v. 687, pp. 255-261, 2013.

[19] CUNHA, S., AGUIAR, J., FERREIRA, V., et al., "Mortars based in different binders with incorporation of phase change materials: Physical and mechanical properties", European Journal of Environmental Civil Engineering, v. 19, pp. 1216-1233, 2015.

[20] AHMAD, M., BONTEMPS, A., SALLÉE, H., et al., "Thermal Testing and Numerical Simulation of a Prototype Cell Using Light Wallboards Coupling Vacuum Isolation Panels and Phase Change Material", Energy and Buildings, v. 38, pp. 673-681, 2006.

[21] CUNHA, S., AGUIAR, J., FERREIRA, V., et al., "Physical and mechanical properties of mortars with incorporation of phase change materials". In : Actas do Congresso Luso-Brasileiro em Materiais de Construção Sustentáveis, v. 3, pp. 145-155, Guimarães, Portugal, Portugal, Mar. 2014.

[22] CUNHA, S., AGUIAR, J., FERREIRA, V., et al., "Durability of mortars with incorporation of phase change materials", In : Actas do Congresso Luso-Brasileiro em Materiais de Construção Sustentáveis, v. 3, pp. 156-168, Guimarães, Portugal, Portugal, Mar. 2014.

[23] CUNHA, S., AGUIAR, J., KHERADMAND, M., et al., "Thermal mortars with incorporation of PCM microcapsules", Restoration of Buildings and Monuments, n. 2/3, v. 19, pp. 171-177, Mar. 2013.

[24] CUNHA, S., AGUIAR, J., FERREIRA, V., et al., "Influence of adding encapsulated phase change materials in aerial lime based mortars", Advanced Materials Research, n. 1, v. 687, pp. 255-261, Apr. 2013.

[25] EUROPEAN COMMITTEE FOR STANDARDIZATION (CEN), EN 1015-3, "Methods of test for mortar for masonry - Part 3: Determination of consistence of fresh mortar (by flow table)", 1999.

[26] AGUIAR, J., MOREIRA, P., LUKOWSKI, P., et al., "Ranking procedure for polymeric coatings and hydrophobic agents for concrete protection", Restoration of Buildings and Monuments, n. 4, v. 13, pp. 251264, 2007.

[27] CZARNECKI, L., LUKOWSKI, P., "An usability approach to technical evaluation of the polymer coatings for concrete substrate", In: Proceedings of 2nd International RILEM Symposium on Adhesion between Polymers and Concrete, pp. 173-180, Germany, 1999. 
[28] EUROPEAN COMMITTEE FOR STANDARDIZATION (CEN), EN 1015-11, "Methods of test for masonry - Part 11: Determination of flexural and compressive strength of hardened mortar", 1999.

[29] EUROPEAN COMMITTEE FOR STANDARDIZATION (CEN), EN 1015-12, "Methods of test for mortar for masonry - Part 12: Determination of adhesive strength of hardened rendering and plastering mortars on substrates", 2000.

[30] EUROPEAN COMMITTEE FOR STANDARDIZATION (CEN), EN 1015-18, "Methods of test for masonry - Part 18: Determination of water absorption coefficient due to capillary action of hardened mortar", 2002.

[31] LABORATÓRIO NACIONAL DE ENGENHARIA CIVIL (LNEC), Especificação E 394, "Betões Determinação da absorção de água por imersão", 1993.

[32] EUROPEAN COMMITTEE FOR STANDARDIZATION (CEN), CEN/TS 12390-9, "Testing hardened concrete - Part 9: Freeze-thaw resistance", 2006.

[33] LI, J., XUE, P., HE, H., et al., "Preparation and application effects of a novel form-stable phase change material as the thermal storage layer of an electric floor heating system", Energy and Buildings, n. 8, v. 41, pp. 871-880, Aug. 2009.

[34] HERNÁNDEZ, V., MORILLÓN, D., BEST, R., et al., "Experimental and numerical model of wall like solar heat discharge passive system", Applied Thermal Engineering, n. 17-18, v. 26, pp. 2464-2469, Dec. 2006.

[35] INSTITUTO PORTUGUÊS DA QUALIDADE (IPQ), NP EN 998-1, "Especificações de argamassas para alvenarias - Parte 1: Argamassas para rebocos interiores e exteriores", 2010.

\section{ORCID}

Sandra Cunha https://orcid.org/0000-0002-6384-1355.

José Aguiar http://orcid.org/0000-0003-3954-5721.

Victor Ferreira https://orcid.org/0000-0002-6295-1333

António Tadeu https://orcid.org/0000-0003-2535-8458 